\title{
Dual Energy X-Ray Absorptiometry Measurement of Bone Mineral Content in Newborns: Validation of the Technique
}

\author{
PIERRE M. BRAILLON, BERNARD L. SALLE, JACQUES BRUNET, FRANCIS H. GLORIEUX, \\ PIERRE D. DELMAS, AND PIERRE J. MEUNIER \\ INSERM Unit 234 and Department of Rheumatology and Bone Diseases [P.M.B., P.D.D., P.J.M.] and \\ Department of Neonatalogy [B.L.S., J.B.], Edouard Herriot Hospital, Lyon, France; and Genetics Unit, Shriners \\ Hospital, and Departments of Paediatrics and Surgery, McGill University, Montreal, Canada [F.H.G.]
}

\begin{abstract}
To evaluate the applicability of dual energy $x$-ray bone absorptiometry in newborns, precision and accuracy of the method was tested for very small quantities of mineral ranging from less than $0.5 \mathrm{~g}$ to about $4 \mathrm{~g}$ of hydroxyapatite using a Hologic QDR 1000 instrument. For six femurs excised from preterm stillborns, the mean precision for bone mineral content (BMC) and bone mineral density (BMD) was 1.2 and $0.8 \%$, respectively. Accuracy based on ash weight indicated a mean overestimation of about $7 \%$. In vivo, the precision was assessed by measuring lumbar spine BMC and BMD (L1 to L5) two or three times in 10 newborns (gestational age, 33 to $40 \mathrm{wk}$ ). The mean coefficients of variation were 2.40 and $1.55 \%$ for BMC and BMD, respectively. Lumbar spine BMC and BMD were also measured once in 30 full-term infants. Values ranged from 1.17 to $3.90 \mathrm{~g}$ for $\mathrm{BMC}$ and from 0.192 to $0.356 \mathrm{~g} / \mathrm{cm}^{2}$ for BMD. The present study shows that dual energy $x$-ray absorptiometry provides a valuable new tool for the assessment and management of BMC in low birth weight infants and neonates in general. (Pediatr Res 32: 77-80, 1992)
\end{abstract}

\section{Abbreviations}

$B L$, birth length

BMC, bone mineral content

BMD, bone mineral density

BW, birth weight

DXA, dual energy x-ray absorptiometry

EDE, effective dose equivalent

HAP, hydroxyapatite

rem, roentgen-equivalent-man

uhr, ultra high resolution

BMCf, standard mode of BMC determination

GA, gestational age

Precise measurement of $\mathrm{BMC}$ in neonates is of great interest, especially for assessing skeletal changes in very low BW premature babies. In recent years, measurements were performed with single photon absorptiometers using an isotopic source of iodine (1-7). The results obtained were limited to the BMC estimate of the forearm or humerus and the mean precision of the method

Received February 19, 1991; accepted January 31, 1992.

Correspondence: P. Braillon, Pavillon F, Hôpital Edouard Herriot, Place d'Arsonval, 69437 Lyon Cedex 03, France. was rather low, ranging from 4 to $14 \%$ with repositioning (8-11) and from 1.1 to $3 \%$ without repositioning $(12,13)$. Recently, interesting results were also obtained by dual energy radiographic densitomety in preterm infants maintained in their incubators (14), but to our knowledge no study using dual photon absorptiometry for the measurement of the spine bone density in newborns has been reported.

To achieve such measurements with precision, two main problems have to be solved. First, the system used must be able to measure very small quantities of mineral, about $2.5 \mathrm{~g}$ or less of HAP for the whole lumbar spine, and, second, the measurement must be done in a very short time (about $3 \mathrm{~min}$ or less) to avoid heavy sedation of the infant. The introduction of DXA provided new perspectives for these measurements (15), based on its high precision, low radiation dose, and short measurement time.

In the present study, we used DXA to measure lumbar spine $\mathrm{BMC}$ in newborns. Our aim was to evaluate the precision and accuracy of the method and to define the normal BMC and BMD values for the lumbar spine in full-term newborns.

\section{MATERIALS AND METHODS}

All of the measurements were performed on a Hologic QDR 1000 densitometer (Hologic, Inc., Waltham, MA). This system works with a pulsed, dual energy $x$-ray source $(70-140 \mathrm{kV})$. The thin $\mathrm{x}$-ray pencil beam obtained after collimation (diameter 0.23 $\mathrm{mm}$ ) passes through a calibration disk and scans in a serpentine $x-y$ pattern the chosen region of interest. A detector, mechanically connected to the $\mathrm{x}$-ray source and mounted above the patient, feeds a computer with the absorption data recorded pixel by pixel for both soft tissue and bone. When theoretically calculated, the absorption is directly related to the coefficients of absorption and to the amount of each component. Because the surface area of the scanned bones is calculated, the results can be expressed both as BMC (in $\mathrm{g}$ of HAP) and BMD (in $\mathrm{g} / \mathrm{cm}^{2}$ HAP). Before initiating measurements in vivo, a precise determination of the delivered $\mathrm{x}$-ray dose was made with a radiation meter (model 36150; Keithly Instruments, Inc., Cleveland, OH). The lower limit of detection on this ion chamber in the integrating mode, the relevant one in this application, is $10^{-9} \mathrm{~Sv}(0.1$ $\mu \mathrm{rem})$. Then, this radiation meter was preferred to other systems such as lithium fluoride dosimeters, which are used for higher radiation doses, and the instrument was scanned three times in the standard conditions for the spine scanning.

Measurements were done on six femurs collected from preterm stillborns with GA from 25 to 39 wk. The specimens, placed in a polyethylene container filled with $5 \mathrm{~cm}$ of water, were measured in triplicate on their entire length over three sessions (nine 
measurements). One femur (no. 5) was measured on two different days and with water thickness increased by $1-\mathrm{cm}$ steps from 4 to $10 \mathrm{~cm}$. Measurements without repositioning were done three times for each thickness.

To estimate the precision in vivo, the lumbar spine (L1-L5) of 10 newborns (GA, 33 to $40 \mathrm{wk}$ ) was measured two or three times with repositioning. Finally, 30 normal, full-term infants ( 14 boys and 16 girls) were studied once, also in their first day of life, to establish normal BMC and BMD values. Some of these infants were sedated ( $1 / 2$ suppository of butobarbital, $30 \mathrm{mg}$ ).

The parents were clearly informed and gave their agreement for these measurements. The study was approved by the Ethics Committee of the Universite Claude Bernard in Lyon.

Scanning and analysis methods. The QDR 1000 scanning system provides a special high-resolution data acquisition and analysis mode for the measurement of small bones. In this mode, the data are obtained with a smaller collimator and an 8-fold increased sampling. However, scanning an infant spine in this mode would take 8 to $10 \mathrm{~min}$, which we considered too long. Therefore, for the present measurements, we used the standard spine data acquisition mode, which permitted 2- to 3-min scans. Two different analysis protocols were used. In the first one, a modification of the standard spine analysis protocol, precise $\mathrm{BMC}$ determination (BMCf) was obtained by filling in the frame containing the area to be measured (Fig. $1 A$ ). With this method, BMD cannot be calculated correctly because the frame area does not correspond to the bone area. Thus, a second approach using a uhr analysis protocol was preferred. Although this protocol did not alter the image resolution, it used a lower threshold detection and therefore correctly identified bone edges, which appeared as dotted lines surrounding the vertebrae (Fig. $1 B$ ).

These programs also calculate the value of $\mathrm{d} \varnothing$, a parameter related to soft tissue thickness. This parameter provided a simple method to estimate the water thickness equivalent for the soft tissue component in the region studied.

Chemical analysis of femurs. To evaluate the accuracy of the densitometric analyses, the six measured femurs were ashed in a muffle furnace at $600^{\circ} \mathrm{C}$ for $16 \mathrm{~h}$ and the ashes were weighed. They were then dissolved in hydrochloric acid $(1 \mathrm{~N} \mathrm{HCl})$ and the calcium content was assessed colorimetrically.

\section{RESULTS}

Irradiation dose. The mean irradiation dose measured three times in the standard scanning conditions was $27.5 \pm 0.2 \mu \mathrm{Sv}$ $(2.75 \pm 0.02 \mathrm{mrem})$.
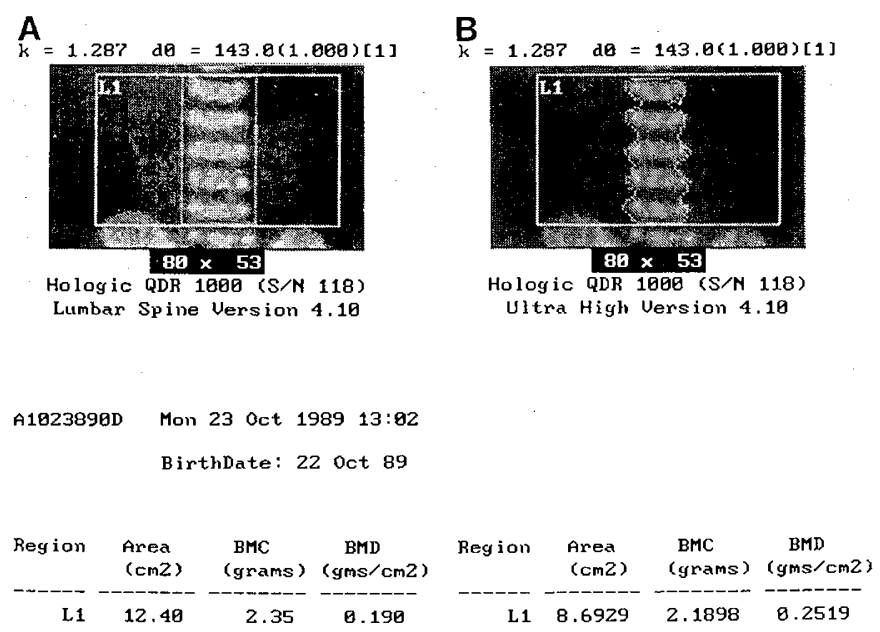

Fig. 1. BMC measured by two protocols in the lumbar spine of the same female infant (GA, $40 \mathrm{wk}$; BW, $3.08 \mathrm{~kg}$; BL, $48.5 \mathrm{~cm}$ ) at $1 \mathrm{~d}$ of age. $A$, determination by filling in a rectangular frame of standard dimensions that included the five lumbar vertebrae: BMCf. $B$, uhr computation protocol: BMCuhr and BMDuhr.
Measurement of accuracy and precision on excised neonatal femurs. The BMC and BMD results obtained from six excised femurs are given in Table 1 with their coefficient of variation. Good correlations were found between BMC and ash weight (Fig. $2 A$ ) and between BMC and the bones' calcium content (Fig. 2B).

The values of BMC and BMD for femur no. 5 immersed in 4 to $10 \mathrm{~cm}$ of water are given in Table 2 . A slight decrease of $1 \%$ in $\mathrm{BMC}$ and $0.9 \%$ in BMD was found with each $\mathrm{cm}$ increment in water thickness.

Precision in vivo. Table 3 shows the results obtained for the lumbar spine of 10 newborns (GA, 33-40 wk) measured two or three times after repositioning. The mean coefficient of variation of the BMCf values was $4.10 \%$, whereas this coefficient was only $2.40 \%$ for the BMCuhr values and $1.55 \%$ for the corresponding BMDuhr values.

$d \emptyset$ values. $\mathrm{d} \emptyset$ values corresponding to a decrease in water thickness from 10 to $4 \mathrm{~cm}$ ranged from 131.6 to 164.0 . These values are highly correlated $(r=1.00)$ with the logarithm of water thickness. They are similarly correlated to water thickness in a linear fashion with a good approximation (Fig. 3). From the results obtained in 30 full-term babies measured during their first $24 \mathrm{~h}$ of life, we found that $\mathrm{d} \emptyset$ values were in the range of 152.7 to 137.7 , corresponding to 5.8 and $8.6 \mathrm{~cm}$ of water, respectively. The mean value was $145.6 \pm 0.7(7.10 \pm 0.15 \mathrm{~cm}$ of water equivalent).

Lumbar spine BMC and BMD values. For all measurements in vivo, on full-term as well as preterm babies, BMCf and BMCuhr were highly correlated $(r=0.99)$. BMC values appeared also to be well correlated with GA $(r \geq 0.65)$.

The BMCf values measured in the spine of the full-term infants ranged from 1.17 to $4.01 \mathrm{~g}$, very close to the more precise values obtained with the uhr calculation mode (1.171 to $3.905 \mathrm{~g}$ ). Good correlations were also found between BMC or BMD values and body length ( $r=0.75$ and 0.61 , respectively).

\section{DISCUSSION}

BMC measurements in small infants are of great interest in many situations, but most specifically in the follow-up of osteopenia. Up to now, the most interesting results were obtained with single photon absorptiometry, which measured BMC at the level of the forearm. Nevertheless, as underlined by Lyon et al. (14), only a short segment of bone is investigated in these measurements and changes in the whole bone cannot be deduced easily from those partial estimates. Moreover, a precise repositioning is very difficult, and this is highly restrictive in longitudinal studies. From our experience in bone densitometry in adults and children (16), we deduced that measurement of the lumbar spine would be more representative of the entire skeleton than measurement of the forearm. However, such measurements are quite difficult in small infants because they involve very small amounts of mineral, about $2.5 \mathrm{~g}$ or less of HAP in normal newborns. In addition, they must be done in a short time to avoid errors due to the movements of infants not completely sedated.

The radiation dose must also be very low. The value that was obtained in this study for the entry dose was as low as 2.75 mrem. A similar value $(22.6 \mu \mathrm{Sv}$ or $2.26 \mathrm{mrem})$ was given by Pye et al. (17), but as shown by these authors, the mean EDE for spine or hip scans with DXA in adult females could be as low as $6.5 \mu \mathrm{Sv}(0.65 \mathrm{mrem})$. They also found that this EDE was similar to the daily background effective dose from natural sources of irradiation in the United Kingdom. Such values may also be compared with the EDE for a standard chest $\mathrm{x}$-ray, which is about 10 times higher, and with the dose of radiation absorbed by the embryo or fetus when a pregnant woman undergoes a lumbosacral spine x-ray examination, which is 1000 times higher (18).

In our experience, with more than 600 measurements on a spine phantom containing 57.3 g of HAP, the QDR $1000 \mathrm{DXA}$ 
DXA MEASUREMENT OF BMC IN NEWBORNS

Table 1. BMC and BMD values with their coefficients of variation (CV) for six excised femurs from fetuses with GA from 25 to 39 wk (BMCuhr and BMDuhr values are given with four decimals because they were obtained with uhr protocol)

\begin{tabular}{ccccccc}
\hline Femur no. & BMCf $(\mathrm{g})$ & CV $(\%)$ & BMCuhr $(\mathrm{g})$ & CV $(\%)$ & BMDuhr $\left(\mathrm{g} / \mathrm{cm}^{2}\right)$ & CV $(\%)$ \\
\hline 1 & 0.96 & 1.04 & 0.8583 & 1.19 & 0.2605 & 0.74 \\
2 & 1.34 & 0.67 & 1.1484 & 1.25 & 0.1769 & 0.70 \\
4 & 0.40 & 1.12 & 0.3295 & 1.23 & 0.1829 & 0.55 \\
4 & 0.61 & 1.04 & 0.5393 & 1.19 & 0.321 & 0.3268 \\
5 & 2.58 & 0.22 & 2.3263 & 1.37 & 0.3034 & 0.99 \\
6 & 2.13 & 1.41 & 1.9222 & $1.18 \pm 0.17$ & & $0.78 \pm 0.16$ \\
\hline
\end{tabular}
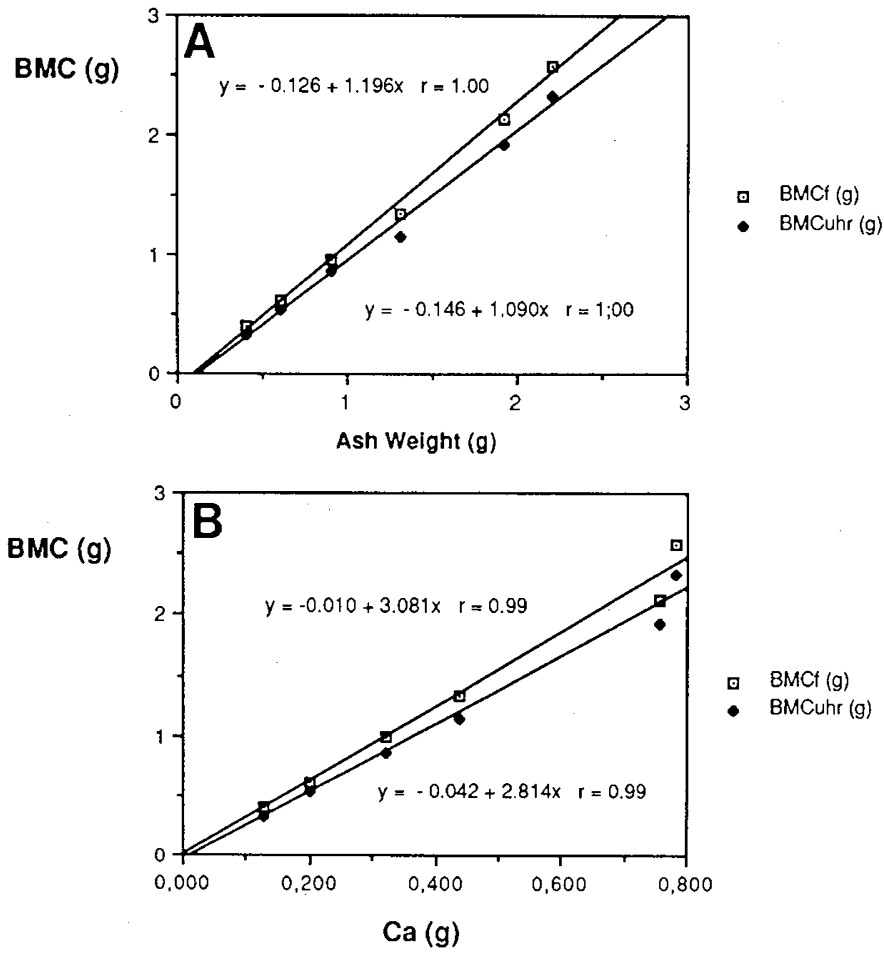

Fig. 2. Correlations between BMCf or BMCuhr (g) of six excised fetal femurs measured in three sessions, three times in each session. $A$, ash weight $(\mathrm{g})$ and $B$, calcium content of the femurs as measured by chemical analysis.

system gives a precision of $0.44 \%$. Our current results from BMC measurements of excised femurs showed that this system is also able to measure very small quantities of mineral with a mean precision better than $1.5 \%$. The coefficient of variation values (\%) found in the present study were similar to those recently published for measurements of the lumbar spine, the proximal tail (19), and long bones (20-22) in rats.

High correlations were found between BMC and ash weight. Similar coefficients for the same correlations were found by Ho et al. (23), but their results were obtained on larger amounts of mineral (from $5 \mathrm{~g}$ to more than $20 \mathrm{~g}$ ). These authors reported also a systematic difference between BMC values and ash weight. However, this difference could not be considered as a good parameter to estimate the accuracy of the method, inasmuch as in ashes elements other than HAP have to be taken into account. In the present study, we found that the measured BMCuhr values were the most accurate, with a mean overestimation of about $7 \%$ in the range concerned.

It also appeared that the uhr computation was the more appropriate of the two protocols used, BMDuhr values being estimated with a mean precision better than $1 \%$ in vitro and $1.6 \%$ in vivo. For lumbar BMC in full-term newborns, an important improvement in the precision of the results was also obtained with the uhr protocol (mean coefficient of variation values, $2.40 \%$ versus $4.10 \%$ for BMCuhr and BMCf, respectively). These findings indicated that the SD is about $71 \%$ higher for results obtained by filling in a frame containing the region of interest than that calculated by the uhr protocol, even with very careful choice of the standard dimensions for the frame.

To estimate soft tissue thickness and its evolution with age or treatment, the $\mathrm{d} \varnothing$ parameter appeared useful. However, it may have to be calculated for each machine independently because it could be dependent on the calibration system. The results obtained on femur no. 5 in various water thicknesses showed a decrease of $1 \%$ in BMCuhr and $0.9 \%$ in BMDuhr per $\mathrm{cm}$ of water. It may be interesting to discuss this point in the future, when individual longitudinal follow-up studies will be available.

In a recent paper, Rubinacci et al. (24) reported on a sexrelated difference in BMC of the forearm in 45- \pm 19 -d-old infants. We found no significant difference in the spine BMC or BMD values of either boys or girls. Similarly, no difference was found for BMC in 1- to 12-y-old children (16). From this previous study, it is interesting to extrapolate to age 0 the curve for the mean BMD value. This gives an estimation of $0.335 \mathrm{~g} / \mathrm{cm}^{2}$, in good agreement with the present results.

BW and BL of full-term newborns were highly correlated $(r=$ $0.92)$. In consequence, it was not surprising that BMC, which is obviously related to vertebral height, was also well correlated with BW and BL. However, the ratios from the maximum to minimum values for $\mathrm{BW}$ and $\mathrm{BL}$ were 1.85 and 1.23 , respectively, whereas the ratio from the maximum to minimum BMC

Table 2. Mean BMC and BMD values with their coefficients of variation $(C V)$ for seven series of three measurements performed on femur no. 5 immersed in $4-10 \mathrm{~cm}$ of water

\begin{tabular}{ccccc}
\hline $\begin{array}{c}\text { Water thickness } \\
(\mathrm{cm})\end{array}$ & BMCuhr $(\mathrm{g})$ & $\mathrm{CV}(\%)$ & BMDuhr $\left(\mathrm{g} / \mathrm{cm}^{2}\right)$ & $\mathrm{CV}(\%)$ \\
\hline 4 & 2.4007 & 0.43 & 0.3386 & 0.58 \\
5 & 2.3263 & 0.85 & 0.3268 & 0.78 \\
6 & 2.3276 & 1.18 & 0.3272 & 0.50 \\
7 & 2.3181 & 0.47 & 0.3296 & 0.73 \\
8 & 2.2644 & 1.26 & 0.3240 & 0.3249 \\
9 & 2.2764 & 1.05 & 0.3083 & 0.36 \\
10 & 2.2236 & 1.06 & $0.3256 \pm 0.0090$ & $0.63 \pm 0.25$ \\
\hline
\end{tabular}


Table 3. Mean values and coefficients of variation $(C V)$ for BMC and BMD of lumbar spine obtained with standard ( $f$ ) and high-resolution (uhr) mode in 10 normal newborns on their first day of life

\begin{tabular}{|c|c|c|c|c|c|c|c|c|c|c|}
\hline Patient & $\begin{array}{l}\text { GA } \\
\text { (wk) }\end{array}$ & Sex & $\mathrm{BW}(\mathrm{g})$ & $\begin{array}{c}\text { Times } \\
\text { measured }\end{array}$ & $\begin{array}{c}\text { BMCf } \\
(\mathrm{g})\end{array}$ & CV (\%) & $\begin{array}{l}\text { BMCuhr } \\
(\mathrm{g})\end{array}$ & $\mathrm{CV}(\%)$ & $\begin{array}{l}\text { BMDuhr } \\
\left(\mathrm{g} / \mathrm{cm}^{2}\right)\end{array}$ & $\mathrm{CV}(\%)$ \\
\hline 1 & 35 & M & 2080 & 3 & 1.98 & 4.36 & 1.9222 & 2.98 & 0.2460 & 0.84 \\
\hline 2 & 40 & M & 3260 & 3 & 2.90 & 2.79 & 2.8422 & 0.88 & 0.3041 & 0.69 \\
\hline 3 & 34 & $\mathrm{~F}$ & 2410 & 3 & 1.97 & 6.62 & 1.7432 & 2.52 & 0.2276 & 1.09 \\
\hline 4 & 36 & $\mathbf{M}$ & 2600 & 2 & 2.67 & 3.97 & 2.4659 & 1.10 & 0.2983 & 0.21 \\
\hline 5 & 39 & M & 3740 & 2 & 2.07 & 6.83 & 1.9298 & 5.47 & 0.2282 & 3.56 \\
\hline 6 & 40 & M & 3570 & 2 & 2.94 & 3.85 & 2.7954 & 0.89 & 0.3071 & 0.14 \\
\hline 7 & 40 & M & 3750 & 2 & 3.07 & 8.51 & 2.9778 & 6.00 & 0.2831 & 3.17 \\
\hline 8 & 33 & $\mathrm{~F}$ & 2790 & 2 & 2.35 & 0.00 & 2.1601 & 1.37 & 0.2538 & 0.70 \\
\hline 9 & 35 & $\mathrm{~F}$ & 2240 & 2 & 2.59 & 3.82 & 2.2961 & 1.54 & 0.2723 & 2.13 \\
\hline 10 & 40 & $\mathrm{~F}$ & 3160 & 2 & 2.41 & 0.29 & 2.3061 & 1.25 & 0.2591 & 2.92 \\
\hline $\begin{array}{l}\text { Mean } \\
\pm 1 \mathrm{SD}\end{array}$ & $\begin{array}{l}37.2 \\
\pm 2.86\end{array}$ & & $\begin{array}{r}2960 \\
\pm 623\end{array}$ & & $\begin{array}{r}2.50 \\
\pm 0.41\end{array}$ & $\begin{array}{r}4.10 \\
\pm 2.72\end{array}$ & $\begin{array}{r}2.34 \\
\pm 0.42\end{array}$ & $\begin{array}{r}2.40 \\
\pm 1.89\end{array}$ & $\begin{array}{r}0.268 \\
\pm 0.030\end{array}$ & $\begin{array}{r}1.55 \\
\pm 1.28\end{array}$ \\
\hline
\end{tabular}

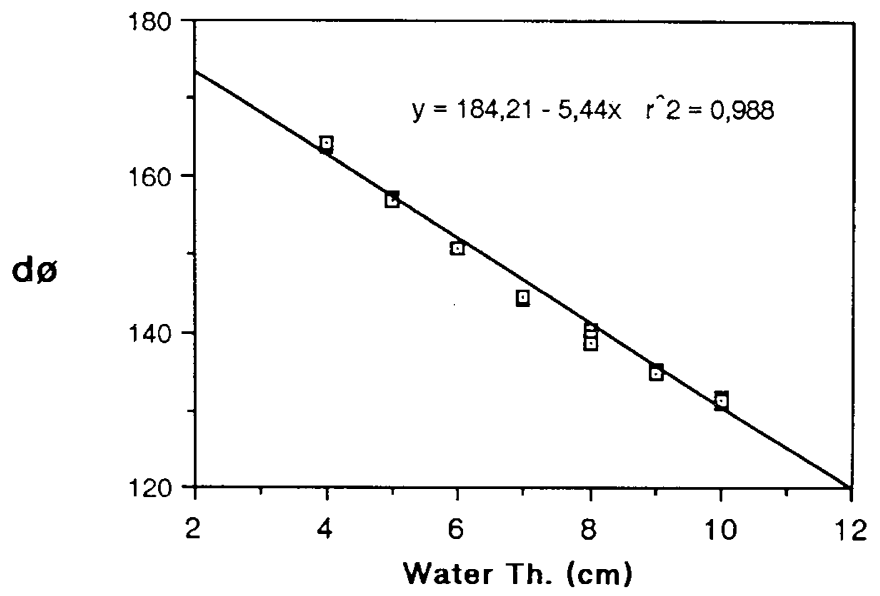

Fig. 3. dø values obtained when measuring one femur (no. 5) immersed in water of various thickness. Triplicate measurements were done for every $1 \mathrm{~cm}$ increment from 4 to $10 \mathrm{~cm}$.

values was higher than 3.3. These differences showed that large variations in $\mathrm{BMC}$ and $\mathrm{BMD}$ could be found in full-term newborns of identical $\mathrm{BW}$ and $\mathrm{BL}$ and thus that the soft tissue component could also be important to measure. Recent preliminary results along these lines appear to be of great interest (25).

In conclusion, our results show that, using a special highresolution program of calculation, amounts of mineral as low as 1 or $2 \mathrm{~g}$ of HAP can be measured with a mean precision of better than $1.2 \%$ in vitro. Moreover, consistent values for BMD can be obtained with a precision better than $1 \%$ in vitro. These preliminary results also indicate that the DXA measurement of $\mathrm{BMC}$ or BMD of the lumbar spine in infants can be performed with a precision better than 2.4 and $1.5 \%$, respectively. The study also provides reference values for lumbar spine BMC and BMD in full-term babies. Finally, it shows the potential of this method for the longitudinal prospective evaluation of preterm infants at risk for developing osteopenia and/or rickets.

Acknowledgments. The authors thank M.F. Meary and B. Guy for their help in managing DXA investigations, and Dr. M.C. Chapuy, C. Fadat, E. Barbey, and S. Arnaud for their assistance in chemical analysis of bones. P.M.B. is grateful to P. Steiger and T. Kelly for their comments.

\section{REFERENCES}

1. Steichen JJ, Kaplan B, Edwards N, Tsang RC 1976 Bone mineral content in full-term infants measured by direct photon absorptiometry. AJR 126:12841285

2. Minton SD, Steichen JJ, Tsang RC 1979 Bone mineral content in term and preterm appropriate for gestational age infants. J Pediatr 95:1037-1042
3. Greer FR, Lane J, Weiner S, Mazess RB 1983 An accurate and reproducible absorptiometric technique for determining bone mineral content in newborn infants. Pediatr Res 17:259-262

4. Chan GM, Leeper L, Book LS 1987 Effects of soy formulas on mineral metabolism in term infants. Am J Dis Child 141:527-530

5. Evans WD, Owen GM, Dohl R, Murphy JF 1987 The measurement of bone mineral content in pre-term infants. Phys Med Biol 32:927(abstr)

6. Steichen JJ, Steichen Asch PA, Tsang RC 1988 Bone mineral content measurement in small infants by single photon absorptiometry: current methodologic issues. J Pediatr 113(suppl):181-187

7. Vyhmeister NR, Linkhart TA 1988 Measurement of humerus and radius bone mineral content in term and preterm infants. J Pediatr 113(suppl):188-195

8. Linkhart TA, Ghosh B, Baylink D, Vyhmeister N 1984 Measurement of preterm infant humerus bone mineral content with the Norland bone densitometer 278A. Calcif Tissue Int 36:493(abstr)

9. Vyhmeister NR, Linkhart TA, Hay S, Baylink DJ, Ghosh B 1987 Measurement of bone mineral content in the term and preterm infant. Am J Dis Child 141:506-510

10. Hillman LS, Chow W, Salmon SS, Weaver E, Erickson M, Hansen J 1988 Vitamin D metabolism, mineral homeostasis and bone mineralization in term infants fed human milk, cow milk-based formula, or soy-based formula. J Pediatr 112:864-874

11. Prentice A, Laskey A, Shaw J, Cole TJ, Fraser DR 1990 Bone mineral content of Gambian and British children aged 0-36 months. Bone Miner 10:211224

12. Pohlandt $F$, Mathers $N 1989$ Bone mineral content of appropriate and light for gestational age preterm and term newborn infants. Acta Paediatr Scand 78:835-839

13. Pittard WB, Geddes KM, Sutherland SE, Miller MC, Hollis BW 1990 Longitudinal changes in the bone mineral content of term and premature infants. Am J Dis Child 144:36-40

14. Lyon AJ, Hawkes DJ, Doran M, McIntosh N, Chan F 1989 Bone mineralisation in preterm infants measured by dual energy radiographic densitometry. Arch Dis Child 64:919-923

15. Barden HS, Mazess RB 1988 Bone densitometry in infants. J Pediatr 113(suppl): 172-177

16. Glastre C, Braillon P, David L, Cochat P, Meunier PJ, Delmas PD 1990 Measurement of bone mineral content of the lumbar spine by dual energy $\mathrm{X}$-ray absorptiometry in normal children: correlations with growth parameters. J Clin Endocrinol Metab 70:1330-1333

17. Pye DW, Hannan WJ, Hesp R 1990 Effective dose equivalent in dual X-ray absorptiometry. Br J Radiol 63:149

18. ICRP Report on Radiation Protection 1989 Summary of the Current ICRP Principles for Protection of the Patient in Diagnostic Radiology. Pergamon Press, Oxford, UK

19. Ammann P, Rizzoli R, Slosman DO, Bonjour JP 1990 Sequential and precise in vivo measurement of bone mineral density (BMD) in rats using dual energy X-ray absorptiometry (DXA). J Bone Miner Res 5S:89(abstr)

20. Listrat V, Roux Ch, Roudier R, Debregeas P, Dougados M 1990 Evaluation of bone mass of small laboratory animals with dual energy X-ray absorptiometry (DEXA-HOLOGIC QDR 1000): precision and accuracy. J Bone Miner Res 5S:93(abstr)

21. Mitlak BH, Rodda CP, Von Deck MD, Dobrolet NC, Kronenberg HM, Neer RM, Nussbaum SR 1990 Pamidronate (APD) preserves bone mass in a gene transfer model of hyperparathyroidism. J Bone Miner Res 5S:168A(abstr)

22. Braillon P, Tsouderos Y, Deloffre P, Bonnet J, Meunier PJ 1991 DEXA measurements of rat femur bone mineral content. A new tool for experimental studies. Calcif Tissue Int 48S:A75(abstr)

23. Ho CP, Kim RW, Schaffler MB, Sartoris DJ 1990 Accuracy of dual energy radiographic absorptiometry of the lumbar spine: cadaver study. Radiology 176:171-173

24. Rubinacci A, Moro GE, Resmini G, Fulconis F, Tessari L, Minoli I, Raiha NCR 1990 Sex-related differences of bone mineral content in low birthweight infants fed cow's milk formula. Acta Paediatr Scand 79:866-868

25. Chan GM 1990 The use of the dual X-ray absorptiometry in infants. J Bone Miner Res 5S:236(abstr) 